\title{
A developmental perspective on adolescent psychoanalytic psychotherapy. An Italian study with the Adolescent Psychotherapy Q-Set
}

\author{
Mauro Di Lorenzo ${ }^{1,2}$, Alfio Maggiolini ${ }^{1,2}$, \& Virginia Anna Suigo ${ }^{1}$
}

\begin{abstract}
Introduction: despite large and widely accepted research on effectiveness, most of psychotherapy research has been done with adults; few studies have been published on the process of adolescent psychotherapy, due to the complexity of the subject and the absence of instruments sensitive enough to empirically capture its nuances. Within psychoanalytic framework, a developmental approach is particularly helpful in the psychotherapy of adolescents. Objective: the purpose of this study was to investigate the typical features of Italian Adolescence Psychodynamic Psychotherapy and its similarities and differences with other adolescence psychotherapeutic approaches; We also aimed at analyzing typical therapists' responses to adolescent patients. Method: 50 italian adolescence psychotherapists filled a brief questionnaire about their clinical expertise, completed the Adolescent Psychotherapy Q - Set (APQ) and the Therapist Response Questionnaire (TRQ) in order to describe their "actual" practice with adolescents. Results: therapeutic process is characterized by a priority to helping adolescent make sense of his own experience, it focuses on present relationships and emotions rather than on past. Strong similarities with Mentalization Based Therapy, mild and no correlations with CognitiveBehavioral Therapy and Classical Psychoanalysis respectively were found; towards adolescents therapists generaly display positive and protective countertransference responses. They less frequenlty show negative responses as overprotection, hostility or feeling of overwhelming. Conclusions: APQ and TRQ can provide meaningfull information about adolescent psychotherapy process. Instruments' improvement (i.e. reviewd items for APQ) and future perspectives are also discussed.
\end{abstract}

Keywords: adolescent psychotherapy research; prototypical treatment; countertransference

Research on evidence-based practice shows a widely accepted, significant and large positive effect of psychotherapy (American Psychological Association, 2013). Psychoanalysis and psychoanalytic psychotherapy have proven effective (Town, Diener, Abbass, Leichsenring, Driessen, \& Rabung, 2012), as widely discussed in two recent volumes: Psychodynamic Psychotherapy Research (Levi, Ablon, Kächele, 2011) and Handbook of Evidence Based Psychodynamic Psychotherapy (Levi, \& Ablon 2009). However, the link between the aims of psychoanal-

\footnotetext{
${ }^{1}$ Minotauro IACA;

${ }^{2}$ Department of Psychology,University of Milano - Bicocca;

${ }^{\square}$ Correspondig Author: Mauro Di Lorenzo, Minotauro IACA; email to: dilorenzo.mauro1@gmail.com
}

ysis and the patients' changes is still unclear. For example, from a relational point of view, we need to understand how to get from "My therapist and I are bonding" to "my marriage, my anxiety, and tics are better" (Kadzin, 2007, p. 8). Moreover, the connection between science and the practice of psychotherapy is still "a tenuous one, at best" (Castonguay, \& Muran, 2015; p. 1): clinicians are not substantially or primarily guided by empirical findings in their clinical practice (Safran, Abreu, Ogilvie, \& DeMaria, 2011) and research is viewed by many clinicians as both irrelevant and alien to their routine work (Castonguay, Locke, \& Hayes, 2011).

While the field of research on effectiveness is large and widely accepted, it has mostly involved adults; few studies have focused on the process of 
adolescent psychotherapy and empirical research on adolescent psychotherapy is still sparse (Kadzin, 2004). Although there is now a considerable body of research assessing the effectiveness of various psychotherapies addressing adolescents presenting a wide range of disorders (e.g. Fonagy et al., 2002), few studies attempt to link specific processes to outcomes in relation to particular modalities of treatment (Bychkova, Hillman, Midgley, \& Schneider, 2011). Interestingly, within the 19 manualized psychodynamic treatments reported in Levi and colleagues' work (2011), including Brief Relational Psychotherapy (Safran, \& Muran, 2000) and Mentalization Based Treatment for Borderline Personality Disorder (Bateman, \& Fonagy, 2006), a specific focus on adolescent patients is still missing. This may be due to the inherent complexity of the subject, and, correspondingly, to the absence of research instruments sensitive and comprehensive enough to empirically capture its nuances (McLeod, \& Weisz, 2005; Bambery, Porcelli, \& Ablon, 2007).

Therapeutic alliance is a good example (Hilsenroth, Cromer, \& Ackerman, 2012; Safran, \& Muran 2000). The role of alliance in predicting treatment outcome is robust and long established in adult psychotherapy, but research on the therapeutic alliance with adolescents is scarce (Zack, Castonguay, Cosvell, MacAleavey, Adelman, \& Kraus, 2015). Moreover, adolescent psychotherapists face the challenge of building and/or repairing alliances not only with the adolescent, but also with his/her parents and environment, making it far more complex for researchers to capture its influence on the outcome (Creed, \& Kendall, 2005; Shirk, \& Karver, 2011).

The same applies to countertransference (Fauth, 2006). According to Gabbard (1995), countertransference is an emerging common ground for psychotherapists with diverse theoretical backgrounds. The distinctive features of the therapist and the therapeutic relationship play a decisive role in the therapeutic process and outcome: research on how therapists manage countertransference reactions shows that overlooking them might jeopardise the treatment (Gelso \& Hayes, 2007). In comparison to the work with adults, interactions with adolescents and their families bring up particularly complex feelings, which, if unrecognized, can significantly influence the clinician's behaviour in unpredictable and potentially counter-therapeutic ways (Rasic, 2010): moreover, adolescents typically elicit very intense countertransference responses (Sarles, 1998). Despite the clinical relevance of countertransference in adolescent psychotherapy, research studies in this field usually focus on emotional responses to specific clinical populations (i.e. personality disorders, eating disorders) rather than on age groups. Research on adolescent countertransference has been relatively neglected (Brandell, 1992; Showalter, 1985).
Italian Adolescent Psychoanalytic Psychotherapy (IAPP). Adolescent psychoanalytic psychotherapy understands change in terms of development, rather than healing. S. Freud (1905) never spoke about adolescence, while focusing on childhood and puberty. Psychoanalytic thinking on adolescence as a specific developmental phase started with A. Freud (1936) and her work on defence mechanisms; followed by Winnicott (1984) and his understanding of independence and autonomy at the core of this period of life. Blos (1962) described the different phases of adolescence and finally Erikson (1968), focused on the dialectic between identity and role confusion.

Italian Adolescent Psychoanalytic Psychotherapy (IAPP) follows a psychoanalytic tradition, which, in Italy, has combined developmental elements. The influential work of Tommaso Senise and his "brief psychotherapy of individuation" targets the distinctive features of adolescence, and adolescents' developmental need for self-definition and social role (Aliprandi, Pelanda, \& Senise 1990). Arnaldo Novelletto underlined developmental symbolic meanings of symptoms and disruptive behaviours during adolescence (1986).

IAPP's focus on developmental needs overcomes a strictly medical approach, as psychopathology is considered first and foremost the result of maladaptation between the young person and his or her family and social environment (Cicchetti, \& Cohen, 2000; Maggiolini, 2009). Family members are routinely involved in treatment (Maggiolini, \& Pietropolli Charmet, 2004).

Developmental tasks (Havighurst, 1953) facing adolescents include achieving new and more mature relations with others, achieving a masculine or feminine social role, accepting one's physique, achieving emotional independence, preparing for couple relationships and family life, preparing for an economic career, acquiring a set of values and achieving socially responsible behaviour. Maladaptation and breakdown emerge when developmental needs are unmet. The main goal of IAPP is to help the adolescent and his or her environment get a better adaptation and overcome obstacles hampering development, following a psychoanalytic assessment (Lancini 2010; Pietropolli Charmet, Bignamini, Comazzi 2010). Tecniques include (Maggiolini 2009; Pietropolli Charmet, Bignamini e Comazzi 2010): the involvement of family members, as adaptive outcome may equally result out of a change on the adolescent's side, his family, or both; creativity and flexibility, in a combination between psychoanalytic, CBT and other treatment techniques; a decision-making and goal-oriented approach; and a focus on the present and the future, rather than the past, both in the understanding and the treatment of the presenting problems. So far, no studies in Italy have been aimed at linking psychotherapeutic clini- 
cal expertise to empirical research. Thus, it seems useful to empirically identify if IAPP's theoretical perspective is actually grounded in one or more pragmatic prototypical models of intervention.

The role of Adolescent Psychotherapy Q-Set in Adolescent Psychotherapy Research. Adolescent Psychotherapy Q-Set (APQ; Bychkova, Hillman, Midgley, \& Schneider, 2011; Bambery, Porcerelli, \& Ablon, 2007; Calderon, Midgley, Schneider, \& Target, 2013) responds to the need to focus on adolescent psychotherapy research. It is the version for adolescents of the Psychotherapy Process Q-Set (PQS; Jones, 2000), a widely adopted instrument in process research that has played the most relevant and innovative role in linking psychoanalysis with empirical research (Ablon et al., 2011). APQ may help to fill the gap in knowledge about change mechanisms in psychotherapy with adolescents, linking adolescent psychoanalysis and empirical research. First, future studies may describe a prototype of adolescent psychotherapy (i.e. psychotherapy in general) and/or a specific approach (e.g. Mentalization Based Therapy) applied to adolescent patients. Second, in single case studies a specific and real treatment may be compared to these prototypes.

APQ specifically measures psychotherapeutic process with adolescents in particular the analysis of unique and dyadic interaction structures between the therapist and the adolescent patient may have multiple implications in clinical practice and research, and thus fill an existing gap in processoutcome research regarding this population, where in the past single-case studies were mostly anecdotal reports. Despite frequent recommendations, Kazdin (2004) stated that the question of how or why therapy works continues to receive limited attention in youth psychotherapy research. The APQ may be well suited for this task.

Aims and Hypotheses. The purpose of this study was first to investigate, in a standardised language, the typical features of IAPP and its similarities and differences with other adolescent psychotherapeutic approaches. Second, we aimed to identify therapeutic styles within IAPP. Third, to analyse the typical responses of psychotherapists to their adolescent patients. In order to accomplish this purpose, 49 Italian adolescent psychotherapists filled in a brief questionnaire about their clinical expertise, completed the Adolescent Psychotherapy Q-Set (APQ) and the Therapist Response Questionnaire (TRQ) to describe an ideally conducted therapy and a typical emotional response to adolescent patients. In other words, the purpose of this study was to investigate what should ideally go on in clinical practice with adolescents from the theoretical vantage point of view of Italian expert clinicians.

(1) We expected the IAPP prototype to share both
PA, CBT and MBT features. In other words, the majority of IAPP most characteristic features were expected to be an integration between different theoretical perspectives. IAPP is indeed rooted in psychoanalytic theory, nevertheless the attention on decision-making processes and the active role of the therapist make it also similar to the cognitive-behavioural perspective.

(2) We expected two different therapeutic prototypes within IAPP, as the therapists stated to be mainly informed by two distinct theoretical backgrounds (developmental/psychoanaltic). Furthermore we expected the two prototypes to be consistent with the perspective declared by therapists.

(3) We expected to find positive emotional responses to the adolescent patient, differently from the usually reported conflictual or very intense ones (Rasic, 2010; Searles, 1998). This is because the IAPP perspective sees adolescents in their developmental path facing specific tasks rather than engaged in an endless conflict with the adult world, and sees the therapist as an "expert travel companion" (Pellizzari, 2003).

\section{Measures}

Adolescent Psychotherapy Q-Set (Calderon, Midgley, Schneider, \& Target, 2013): the 100 items of the APQ provide a basic language for the description and classification of therapy processes in adolescent psychotherapy treatments. APQ provides an approach with a descriptive, transtheoretical and non-slang language that allows researchers to describe different theoretical orientations. The APQ is neutral with respect to any particular theory of psychotherapy, and permits the portrayal of a wide range of events, interventions, and processes in the psychotherapy process.

Table 1. APQ fixed distribution

\begin{tabular}{|c|c|c|}
\hline 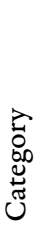 & 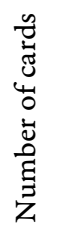 & Label of Category \\
\hline 9 & 5 & Extremely characteristic or salient \\
\hline 8 & 8 & Quite characteristic or salient \\
\hline 7 & 12 & Fairly characteristic or salient \\
\hline 6 & 16 & Somewhat characteristic or salient \\
\hline 5 & 18 & Relatively neutral or unimportant \\
\hline 4 & 16 & Somewhat uncharacteristic or negatively salient \\
\hline 3 & 12 & Fairly uncharacteristic or negatively salient \\
\hline 2 & 8 & Quite uncharacteristic or negatively salient \\
\hline 1 & 5 & Extremely uncharacteristic or negatively salient \\
\hline
\end{tabular}


Three types of items compose APQ: (1) items describing patient's emotional states, attitude, behaviour or experience; (2) items reflecting the therapist's actions and attitudes; and (3) items attempting to capture the nature of the interaction of the dyad, or the climate or atmosphere of the encounter. Each item describes an aspect of psychotherapeutic process in terms of linguistic and behavioural cues, the presence or absence of which can be objectively observed. Following the Q-Sort methodology, APQ raters assign a fixed number of cards (items) to each category (from the most characteristic to the most uncharacteristic; see Table 1).

APQ was similarly used in a study carried out at the Anna Freud Centre (Bychkova et al., 2011), in order to obtain a description of prototypical aspects of different therapeutic approaches: Psychotherapy in general (P), Psychodynamic Psychotherapy (PdP), Psychoanalysis (PA), Cognitive-Behavioural Therapy (CBT), Mentalization-Based Therapy (MBT) and Interpersonal Therapy (IT).

Therapist Response Questionnaire (Betan, Heim, Zittel, \& Westen, 2005; Zittel, \& Westen, 2003): TRQ is a clinician-report instrument designed to assess countertransference patterns in psychotherapy. It consists of 79 items measuring a wide range of cognitive, affective and behavioural responses of the therapists towards their patients. The items assess a range of responses, from simple contents to complex constructs such as projective identification. Clinicians assess each item out of a 5-point Likert scale, ranging from 1 (not true) to 5 (very true). The questionnaire comprises eight countertransference dimensions:

1) Criticized/Mistreated; 2) Helpless/Inadequate; 3) Positive/Satisfying; 4) Parental/Protective; 5) Overwhelmed/Disorganized; 6) Special/Overinvolved; 7) Sexualized; 8) Disengaged.

TRQ was employed in an Italian study aimed at identifying prototypical responses of the therapist towards patients with specific personality disorders (Colli, Tanzilli, Dimaggio, \& Lingiardi, 2014) and in particular with narcissistic patients (Tanzilli, Colli, Muzi, \& Lingiardi, 2015). A recent study involving the use of TRQ targeted young people in a mental health setting to investigate the relation between the emotional responses of the therapists and patient drop-outs (Torres, \& Ribeiro, 2012). An adolescent version is under validation (Countertransference Questionnaire for Adolescents - CQA; Satir, Thompson-Brenner, Boisseau, \& Cristafulli, 2009).

\section{Procedure}

Two authors of the present work have interviewed the therapists (using a brief questionnaire on demographic information and details of their professional practice and qualifications) and provided a guide to the Q-sort methodology. Therapists were asked to use the list of APQ items to rate their ideally conducted therapeutic practice from their theoretical vantage point. To make the APQ sort more manageable, it was divided into two phases: in the first phase, participants assigned an initial rating (Characteristic - Neutral - Uncharacteristic), and in the second, participants revised their ratings until all items were in line with the required Q-sort distribution. The sort was completed by assigning items a rating using a 9-point scale ranging from 1 (extremely uncharacteristic of my clinical practice) to 9 (extremely characteristic of my clinical practice) until they were appropriately distributed. The experts were given the opportunity to provide qualitative feedback on the items, as well as on items they would add to the instrument.

In previous works using PQS to capture an "ideal prototype" from the theoretical vantage points of seasoned clinicians, traditional Q-methodology was modified and raters were asked to rate each item of the manual on a likert scale (i.e from -4 to +4 , see Goodman, Midgley, \& Schneider, 2015). However, in the present study raters placed items following APQ fixed distribution, similar to a normal distribution that characterizes both the high and low ends of a construct. We calculated a raters agreement based on the percentage of cases the 49 therapists agreed upon in relation to item sorting: "characteristic" (pile 6, 7, 8, 9), "uncharacteristic" and "neutral or unimportant" (pile 5). The mean agreement was $61.4 \%$ (Range of agreement: $40.8 \%$ for item 7 "Young person in anxious or tense" and item 88 "Young person fluctuates between strong emotional states during the session" $-98.0 \%$ for item 89 "Therapist makes definite statements about what is going on in the young person's mind"). We also calculated an intraclass correlation between therapists to establish interrater reliability (ICC $=.895$; range: $.861-.923)$. Finally, the therapists described, by answering TRQ items, their typical countertransference reaction to adolescent patients, in comparison to children, couples or adult patients.

\section{Data Analyses}

SPSS 20 for Windows (IBM, Armonk, NY) was used to conduct all of the analyses. Means and modes were calculated in order to describe the prototypical aspects of IAPP and the typical countertransference reactions. We applied Q-factor analysis (Block, 1978) to empirically identify naturally occurring therapeutic styles or countertransference pattern groupings - that is, groups of therapists with attitudes, techniques or emotional responses to adolescent patients similar to one another and distinct from those of therapists in other groupings. The computational algorithms were identical to those of conventional factor analysis but were ap- 
plied to cases rather than variables. In our study, Qfactor analysis identifies groups of similar therapists who share a common therapeutic approach. Spearman's rank correlations were used to investigate the overlap between identified therapeutic styles, while the Mann Whitney $U$ test was used to investigate specific differences between them.

\section{Participants}

A sample of Italian adolescent psychotherapists was recruited during the biannual meeting of AGIPPsA (Association of Italian Adolescent Psychodynamic Psychotherapy Groups). Out of the 150 clinicians contacted and willing to participate, 49 were selected: $28.6 \%$ males $(\mathrm{n}=14)$ and $71.4 \%$ females $(\mathrm{n}=$ 35). All clinicians were selected because of their nationally recognized expertise in adolescent psychoanalytic psychotherapy. They are authors of published papers and manuals about adolescence and psychoanalytic therapy, most of them supervise and teach students undergoing psychotherapy postgraduation training. Regarding the credentials of the 49 expert clinicians, all were practicing therapists who had many years of clinical experience ( $M$ $=17.25, \mathrm{SD}=11.89$; see Table 2 ) working with young people manifesting problems such as suicidality and self-harming behaviour $(59.2 \%$ of the sample), eating disorders (53.1\%), acute social withdrawal (Hikikomori, 46.9\%), learning problems (26.5\%), substance and internet addiction (16.4\%). As adolescent psychodynamic psychotherapy in Italy combines psychoanalytic and developmental elements, we asked the clinicians to specify whether they defined themselves as more "developmentally oriented" $(67.3 \%)$ or "psychoanalytically oriented"
(32.7\%).

Table 2. Length of experience

\begin{tabular}{lccccc}
\hline & $\mathrm{N}$ & Minimum & Maximum & Mean & $\mathrm{SD}$ \\
\hline $\begin{array}{l}\text { Length of } \\
\text { experience } \\
\text { (years) }\end{array}$ & 49 & 4 & 40 & 17,25 & 11,89 \\
\hline
\end{tabular}

\section{Results}

The first aim of the study was to describe IAPP. Tables 3 and 4 show the 13 most characteristic and the 13 most uncharacteristic APQ items, selected by a mode-mean criterion. We first used mode to see which APQ category best describes the most distinctive items; items with the same mode were then sorted by mean. Thirteen is the number of items that fall within the first (extremely un/characteristic; $n=$ 5) and the second (quite un/characteristic; $n=8$ ) category of APQ fixed distribution. IAPP's features focus on making sense of the adolescent's experience (APQ9), an empathic and non-judgmental attitude (APQ18) and a specific interest in the here and the now, in terms of emotional states, inner experience and interpersonal exchange (APQ63, APQ96, APQ97).

Concerning the most uncharacteristic items, IAPP therapists refuse an authoritarian definition of the adolescent's inner states (APQ89), and bear in mind the importance of therapeutic alliance (APQ16, APQ14, APQ1). They try to avoid interpersonal schemas where a competitive motivational system prevails (APQ5, APQ42). Finally, they rarely rely on self-disclosure (APQ21), clarification on their techniques' rationale (APQ57) and active guidance (APQ 27).

Table 3. IAPP most characteristic APQ items

\begin{tabular}{|c|c|c|c|c|}
\hline APQ Item & M & SD & Mode & Label \\
\hline APQ9: Therapist works with young person to try to make sense of experience & 7.98 & 1.4 & 9 & Extremely \\
\hline APQ96: Therapist attends to the young person's current emotional states & 7.86 & 1.18 & 9 & Extremely \\
\hline APQ18: Therapist conveys a sense of non-judgmental acceptance & 7.78 & 1.71 & 9 & Extremely \\
\hline APQ97 Therapist encourages refection on internal states and affects & 6.96 & 1.96 & 9 & Extremely \\
\hline APQ63: Young person discusses and explores current interpersonal relationships & 7.51 & 1.47 & 8 & Quite \\
\hline $\begin{array}{l}\text { APQ65: Therapist restates or rephrases young person's communication in order to clarify its } \\
\text { meaning }\end{array}$ & 7.06 & 1.49 & 8 & Quite \\
\hline $\begin{array}{l}\text { APQ68: Therapist encourages young person to discuss assumptions and ideas underlying experi- } \\
\text { ence }\end{array}$ & 7.02 & 1.57 & 8 & Quite \\
\hline APQ62: Therapist identifies a recurrent pattern in young person's behaviour or conduct & 6.69 & 1.64 & 8 & Quite \\
\hline $\begin{array}{l}\mathrm{APQ} 47 \text { : When the interaction with young person is difficult, therapist accommodates in an effort } \\
\text { to improve relations }\end{array}$ & 6.49 & 1.65 & 8 & Quite \\
\hline APQ79: Young person's experience of his/her body is discussed & 5.92 & 1.81 & 8 & Quite \\
\hline APQ74: Humour is used & 6.78 & 1.69 & 7 & Fairly \\
\hline APQ26: Young person experiences or expresses troublesome (painful) affect & 6.59 & 1.34 & 7 & Fairly \\
\hline APQ60: Therapist draws attention to young person's characteristic ways of dealing with emotion & 6.57 & 1.61 & 7 & Fairly \\
\hline
\end{tabular}


Table 4. IAPP most uncharacteristic APQ items

\begin{tabular}{lcccc}
\hline APQ Item & M & SD & Mode & Label \\
\hline APQ87: Young person is controlling of the interaction with therapist & 3.41 & 1.4 & 3 & Fairly \\
APQ42: Young person rejects therapist's comments and observations & 3.31 & 1.56 & 3 & Fairly \\
APQ5: Young person has difficulty understanding therapist's comments & 3.00 & 1.36 & 3 & Fairly \\
APQ14: Young person does not feel understood by therapist & 3.00 & 1.35 & 3 & Fairly \\
APQ2: Therapist draws attention to young person's non-verbal behaviour & 4.33 & 1.83 & 2 & Quite \\
APQ1: Young person expresses, verbally or non-verbally, negative feelings towards therapist & 3.45 & 1.69 & 2 & Quite \\
APQ81: Young person is controlling of the interaction with therapist & 3.39 & 1.79 & 2 & Quite \\
APQ57: Therapist explains rationale behind technique or approach to treatment & 3.02 & 1.93 & 2 & Quite \\
APQ98: The therapy relationship is a focus of discussion & 3.67 & 2.16 & 1 & Extremely \\
APQ16: Young person fears being punished or threatened & 2.94 & 1.82 & 1 & Extremely \\
APQ21: Therapist self-discloses & 2.94 & 1.92 & 1 & Extremely \\
APQ27: Therapist offers explicit advice and guidance & 2.67 & 1.88 & 1 & Extremely \\
APQ89: Therapist makes definite statements about what is going on in the young person's & 1.73 & 1.06 & 1 & Extremely \\
$\quad$ mind & & & &
\end{tabular}

The second aim of this study was to investigate the similarities and differences between IAPP and other adolescent psychotherapeutic approaches. As there are currently no established prototypes for the final version of the APQ used in this study (Calderon et al., 2013), we used a qualitative comparison between our results and the prototypes $(\mathrm{PA}=$ Psychoanalysis; $\mathrm{CBT}$ = Cognitive Behavioural Therapy; MBT = Mentalization Based Therapy) from Bychkova et al.'s work (2011), after selecting unmodified items only. In order to show the realms of overlap and no overlap between IAPP, psychoanalysis, CBT and MBT, the prototypic items of the four approaches are presented in the form of a Venn diagram (Figure 1; see Leichsenring, Ablon, Barber, Beutel, Gibbons, Crits-Christoph, Klein, Leweke, Steinert, Wiltink, Salzer, 2015). All approaches share 1 item, IAPP shares 4 items with PA, 3 items with CBT and 4 item with MBT.

A close look at the most/least salient items in the typical practice of PA and IAPP revealed that the main similarities between the two approaches were the following: both types of therapists try to make sense of the adolescents' experiences (APQ9), attend to emotional experience (APQ96; APQ97) and express an empathic attitude towards the adolescents' subjective point of view (APQ18). However, AIPP therapists are active, especially in suggesting new points of view and meanings (APQ68; APQ63), and they focus on present relationships with significant others, while PA therapists tend to focus on the therapeutic relationships (APQ98) and unconscious feelings and desires (APQ50) and use transfer interpretation (APQ100).

The main similarities between IAPP and CBT involve the use of clarification and reformulation techniques and the identification of patterns in the adolescent's behaviour (APQ65, APQ62). CBT therapists are more problem-solving oriented, frequently challenge the patients' cognitive schemas and views
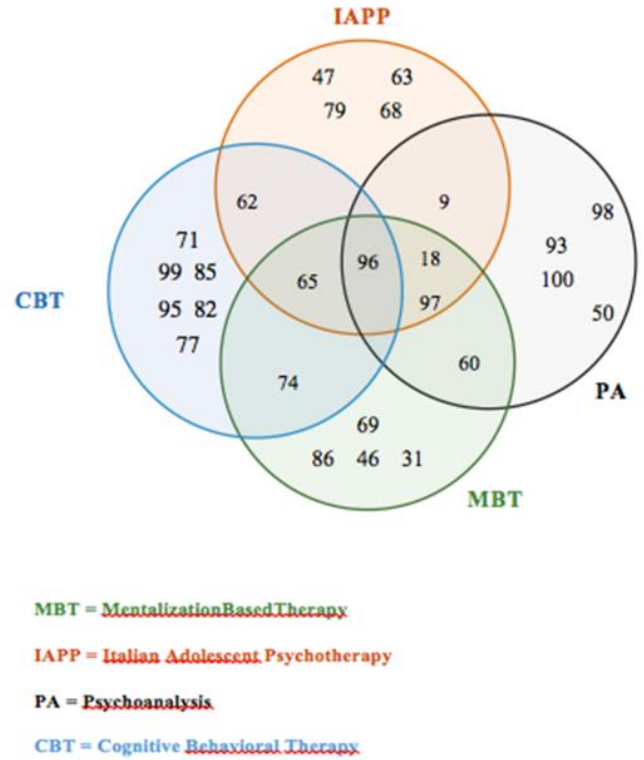

Figure 1. Overlap between IAPP, PA, CBT, and MBT with regard to the prototypic $A P Q$ items.

and explicitly guide them towards new behaviours (APQ82; APQ99; APQ71; APQ85).

Finally, the comparison between MBT and IAPP show similarities in the non-judgemental attitude (APQ18), and the specific focus on emotions, thoughts and feelings underpinning one's and the other's behaviour (APQ97; APQ96). However, MBT therapists focus on internal states and on enhancing reflective functions (APQ69, APQ60), while IAPP therapists' focus is on meanings.

\section{Identifying prototypical approaches in IAPP}

The last research question about IAPP characteristics aimed to identify specific therapeutic styles within the same approach. We applied a Q-factor analysis to identify groups of similar therapists who 
Table 5. Developmental Psychotherapy style

\begin{tabular}{|c|c|c|c|c|}
\hline DP specific features & $\begin{array}{c}\text { Mann- } \\
\text { Whitney U }\end{array}$ & $\mathrm{Z}$ & $p$ & Direction \\
\hline \multicolumn{5}{|l|}{ Characteristic items } \\
\hline APQ97: Therapist encourages refection on internal states and affects & 200.0 & -1.676 & 0.094 & \\
\hline $\begin{array}{l}\text { APQ 47: When the interaction with young person is difficult, therapist acco } \\
\text { modates in an effort to improve relations }\end{array}$ & 237.5 & -0.877 & 0.381 & \\
\hline $\begin{array}{l}\text { APQ60: Therapist draws attention to young person's characteristic ways of } \\
\text { dealing with emotion }\end{array}$ & 203.5 & -1.600 & 0.110 & \\
\hline $\begin{array}{l}\text { APQ62: Therapist identifies a recurrent pattern in young person's behaviou } \\
\text { conduct }\end{array}$ & 151.0 & -2.700 & 0.007 & $\mathrm{DP}>\mathrm{PP}$ \\
\hline $\begin{array}{l}\text { APQ63: Young person discusses and explores current interpersonal relation } \\
\text { ships }\end{array}$ & 169.0 & -2.372 & 0.018 & $\mathrm{DP}>\mathrm{PP}$ \\
\hline APQ74: Humour is used & 258.0 & -0.446 & 0.655 & \\
\hline APQ79: Young person's experience of his/her body is discussed & 220.5 & -1.231 & 0.219 & \\
\hline \multicolumn{5}{|l|}{ Uncharacteristic items } \\
\hline APQ87: Young person is controlling of the interaction with therapist & 113.5 & -3.526 & 0.000 & $\mathrm{PP}>\mathrm{DP}$ \\
\hline $\begin{array}{l}\text { APQ1: Young person expresses, verbally or non-verbally, negative feelings } \\
\text { wards therapist }\end{array}$ & 146.5 & -2.800 & 0.005 & $\mathrm{PP}>\mathrm{DP}$ \\
\hline APQ2: Therapist draws attention to young person's non-verbal behaviour & 257.0 & -0.463 & 0.644 & \\
\hline APQ14: Young person does not feel understood by therapist & 199.0 & -1.423 & 0.155 & \\
\hline APQ44: Young person feels wary or suspicious of the therapist & 132.0 & -3.106 & 0.002 & $\mathrm{DP}>\mathrm{PP}$ \\
\hline APQ16: : Young person fears being punished or threatened & 168.0 & -2.393 & 0.017 & $\mathrm{DP}>\mathrm{PP}$ \\
\hline APQ98: The therapy relationship is a focus of discussion & 218.0 & -1.120 & 0.263 & \\
\hline
\end{tabular}

share a common therapeutic attitude. The scree plot and percentage of variance accounted for were both used to determine the number of factors to rotate, indicating a two-factor solution. Analyses with an Oblimin rotation were then conducted. The two-factor solution accounted for $45.9 \%$ of the variance. $82 \%$ (27 of 33 ) of the therapists who defined themselves as "developmentally oriented" and 19\% of the therapists (3 of 16) who define themselves as "psychoanalytically oriented" loaded into Factor 1 (range of factor loadings: $0.552-0.856$ ). Likewise $18 \%$ (6 of 33 ) of the developmentally oriented therapists and 63\% (10 of 16 ) of the psychoanalytically oriented therapists loaded into Factor 2 (range of factor loading: $0.429-0.767$ ). In order to have a statistical reading of this comparison we performed a Chi Square test (Pearson Chi-

Table 6. Psychoanalytic Psychotherapy Style

\begin{tabular}{|c|c|c|c|c|}
\hline PP specific features & $\begin{array}{c}\text { Mann- } \\
\text { Whitney U }\end{array}$ & $\mathrm{Z}$ & $p$ & direction \\
\hline \multicolumn{5}{|l|}{ Characteristic items } \\
\hline APQ20: Young person is provocative, tests limits of therapy relationship & 112.5 & -3.519 & 0.000 & $\mathrm{PP}>\mathrm{DP}$ \\
\hline APQ3: Therapist's remarks are aimed at facilitating young person's speech & 234.0 & -0.957 & 0.339 & \\
\hline APQ12: Silences occur during the session & 167.5 & -2.238 & 0.019 & $\mathrm{PP}>\mathrm{DP}$ \\
\hline APQ31: Therapist asks for more information or elaboration & 146.5 & -2.804 & 0.005 & $\mathrm{PP}>\mathrm{DP}$ \\
\hline APQ32: Young person achieves a new understanding & 230.0 & -0.877 & 0.381 & \\
\hline $\begin{array}{l}\text { APQ37: Therapist remains thoughtful when faced with young person's str } \\
\text { fect or impulses. }\end{array}$ & 247.5 & -0.485 & 0.628 & \\
\hline \multicolumn{5}{|c|}{ Uncharacteristic items } \\
\hline APQ66: Therapist is directly reassuring & 198.5 & -1.695 & 0.09 & \\
\hline APQ71: Therapist challenges over-generalized or absolute beliefs & 201.0 & -1.639 & 0.101 & \\
\hline APQ33: Therapist adopts a psychoeducational stance & 203.0 & -1.603 & 0.109 & \\
\hline APQ48: Therapist encourages independence in the young person & 159.0 & -2.543 & 0.011 & $\mathrm{DP}>\mathrm{PP}$ \\
\hline APQ54: Young person is clear and organized in self-expression & 227.0 & -1.103 & 0.270 & \\
\hline $\begin{array}{l}\text { APQ67: Young person finds it difficult to concentrate or maintain attenti } \\
\text { the session }\end{array}$ & 246.0 & -0.688 & 0.492 & \\
\hline APQ76: Therapist explicitly reflects on own behaviour, words or feelings & 224.5 & -1.146 & 0.252 & \\
\hline
\end{tabular}


Table 7. Therapists' most characteristic responses

\begin{tabular}{|c|c|c|c|}
\hline Item TRQ & M & SD & Mode \\
\hline TRQ3: I find it exciting working with him/her. & 4.47 & 0.767 & 5 \\
\hline TRQ47: I feel nurturant toward him/her. & 3.81 & 0.842 & 4 \\
\hline TRQ64: I have warm, almost parental feelings toward him/her. & 3.55 & 0.792 & 4 \\
\hline TRQ42: I feel like I want to protect him/her. & 3.53 & 1.023 & 4 \\
\hline TRQ29: S/he tends to stir up strong feelings in me. & 3.41 & 0.84 & 3 \\
\hline TRQ1: I am very hopeful about the gains s/he is making or will likely make in treatment. & 3.41 & 0.762 & 3 \\
\hline TRQ65: I like him/her very much. & 3.27 & 0.884 & 3 \\
\hline TRQ28: I feel guilty when s/he is distressed or deteriorates, as if I must be somehow responsible. & 3.24 & 1.09 & 4 \\
\hline TRQ53: I feel pleased or satisfied after sessions with him/her. & 3.2 & 0.79 & 3 \\
\hline TRQ74: I feel nurturant toward him/her. & 3.14 & 1.19 & 3 \\
\hline
\end{tabular}

Table 8. Therapists' most uncharacteristic responses

\begin{tabular}{|c|c|c|c|}
\hline Item TRQ & M & SD & Mode \\
\hline TRQ70: I return his/her phone calls less promptly than I do with my other patients. & 1.47 & 0.819 & 1 \\
\hline TRQ50: I tell him/her that I love him/her & 1.47 & 0.819 & 1 \\
\hline TRQ56: I find myself being flirtatious with him/her. & 1.43 & 0.816 & 1 \\
\hline TRQ48: I lose my temper with him/her. & 1.41 & 0.674 & 1 \\
\hline TRQ20: I feel envious of or competitive with him/her. & 1.41 & 0.705 & 1 \\
\hline TRQ17: I feel sexually attracted to him/her. & 1.37 & 0.698 & 1 \\
\hline TRQ78: I begin sessions late with him/her more than with my other patients & 1.37 & 0.668 & 1 \\
\hline TRQ62: I feel repulsed by him/her & 1.33 & 0.801 & 1 \\
\hline TRQ57: I feel resentful working with him/her. & 1.31 & 0.585 & 1 \\
\hline TRQ44: I feel like I'm being mean or cruel to him/her & 1.14 & 0.408 & 1 \\
\hline
\end{tabular}

Square $=15.527 ; p=0.000)$. We called the first factor "Developmental Psychotherapy" (DP) and the second factor "Psychoanalytic Psychotherapy" (PP). A Spearman's Rho correlation was performed and we found a mild correlation between the $2 \mathrm{q}$-factors (Rho $=0.719, p=0.000$ ). This finding suggests that the two prototypes are similar but not identical. Finally, we performed Mann-Whitney $U$ tests in order to compare the most characteristic and uncharacteristic features of both styles (see tables 5 and 6).

The "Developmental Psychotherapy" style seems more aligned with a pragmatic decision-making and goal oriented perspective and focuses on identifying dysfunctional relational and emotional cyclical dynamics (APQ62: $\mathrm{U}=151.00, p=0.007$; APQ63: $\mathrm{U}=$ $169.00, p=0.018$ ). The psychotherapist is more active here and feels the adolescent is collaborative and cooperative, rather than defensive (APQ87: $\mathrm{U}=113.5, p$ $=0.000 ; \mathrm{APQ} 1: \mathrm{U}=146.50, p=0.005 ; \mathrm{APQ} 44: U$ $=132.00, p=0.002$; APQ16: $U=168.00, p=0.017$ ). The "Psychoanalytic Psychotherapy" style is aimed at promoting new insights: the therapist frequently asks for more elaboration in order to help the adolescent in the psychoanalytic "working through" (APQ31: $\mathrm{U}=$ $146.50, p=0.005$ ) and may feel the patient is challenging and difficult to manage (APQ20: $\mathrm{U}=112.50, p=$
0.000).

Psychotherapists generally reported protective (TQR factor "Parental/Protective") and positive (TRQ factor "Positive/Satisfying") countertransference responses. Feelings of being "not good enough" as therapist (TRQ factor "Helpless/Inadequate") may occur. Therapists less frequently show negative responses, such as overprotection (TRQ factor "Special/Overinvolved"), hostility (TRQ factor "Hostile/Mistreated") or detachment (TRQ Factor "Disengaged"). Feelings of overwhelmed and sexualized responses were not reported by the therapists (see Table 9).

Table 9 - TRQ factors

\begin{tabular}{lccc}
\hline Countertransference dimension & M & DS & Rank \\
\hline TR Overwhelmed/Disorganized & 1.89 & 0.415 & 7 \\
TR Helpless/Inadequate & 2.32 & 0.526 & 3 \\
TR Positive/Satisfying & 3.11 & 0.412 & 2 \\
TR Special/Overinvolved & 2.15 & 0.628 & 4 \\
TR Disengaged & 2.02 & 0,39 & 6 \\
TR Sexualized & 1.45 & 0.392 & 8 \\
TR Parental/Protective & 3.28 & 0.589 & 1 \\
TR Hostile/Mistreated & 2.07 & 0.637 & 5 \\
\hline
\end{tabular}


We applied Q-factor analysis to identify different pattern of countertransference responses. The scree plot and percentage of variance accounted for were both used to determine the number of factors to rotate, indicating a three-factor solution. Analyses with an Oblimin rotation were then conducted. The three-factor solution accounted for $45.9 \%$ of the variance. We called the first countertransference typical response "Positive/Engaged" pattern: it implies, in addition to the common features, feeling engaged in the therapy and talking to colleagues about adolescent patients more often (TRQ73). Working with young people is considered fruitful, rewarding and interesting (TRQ 53, TRQ 65, TRQ 74). Guilt (TRQ 24) or negative-distressed responses rarely occur. The second typical response, which we called "Avoidant/Disengaged", implies feeling very frustrated (TRQ 22) and angry (TRQ15) and unable to fully engage in the therapy (TRQ9): the therapist moreover explicitly avoids self-disclosure (TRQ13, TRQ32). Finally, the third typical response, what we called the "Compassionate" pattern, implies feeling emphatic and sad about the adolescent's suffering (TRQ18, TRQ4), with the therapist trying to repair and compensate the "damage" caused by the environment (TRQ21, TRQ24).

\section{Discussion}

The present study is a first attempt to apply a research methodology widely used in literature to adolescent psychodynamic psychotherapy in Italy. First, APQ defined IAPP in a standardized manner: IAPP therapists help adolescents make sense of their own experience, focus on present relationships and emotions rather than on the past, discuss what is happening in their lives rather than in the therapeutic relationship, do not confront adolescents in a non-empathic manner and do not let therapeutic alliance disrupt without trying to repair it.

The therapists involved, while confirming that the instrument is sensitive enough to capture the main aspects of their clinical practice, added a few suggestions about possible improvements. In line with their background and clinical practice, therapists suggested items related to the work with adolescents' parents and their "enlarged psychic space" (Jeammet 1980). In their opinion, additional items could also concern the theme of future (e.g. "Future is a focus of the session", or "The therapist encourages the adolescent to think about his/her future") and assertiveness (e.g. "The adolescent feels empowered"; "The therapist encourages the young person to take an active role in his or her life").

We compared IAPP to other approaches. The results are in line with what was expected (hypothesis 1). IAPP combines both psychodynamic and cognitive-behavioural elements and it aims to identify dysfunctional patterns which prevent the adoles- cent from achieving his/her developmental tasks (Havinghurst, 1972), rather than at enhancing reflective functions or promoting a positive therapeutic relationship in itself (Lancini, 2010; Maggiolini, 2009, 2012, 2014; Maggiolini, \& Pietropolli Charmet, 2004). Therefore, IAPP differs from psychoanalysis (as described by Greenspan in 1997) and the Mentalization-based model (as conceptualized by Allen, Fonagy and Bateman in 2008). Similarities with CBT reflect a common goal-oriented and decision-making approach.

We also identified two different therapeutic styles, in line with hypothesis 2 . The first is pragmatic and goal oriented, it works on cyclical psychodynamics, interpersonal problems and affective regulation. Psychotherapists are active and decision-making oriented and adolescents are seen as typically engaged with clinicians in the therapeutic process (Maggiolini, 2009). The second style primarily aims to promote new insights: the therapist frequently asks for more elaboration in order to help the adolescent in the psychoanalytic "working through" and may feel the patient is challenging and difficult to manage (Aliprandi et al., 1990). This finding indicates that with APQ it is possible to identify different therapeutic attitudes within a sample of expert clinicians, which share highly similar conceptualization of the practice of psychotherapy (Levy, Ablon, Kächele, 2011).

We then focused on countertransference, through the Therapist Response Questionnaire. Westen and Gabbard (2002) suggest that patients with specific personality patterns tend to elicit certain foreseeable countertransference reactions. IAPP therapists tend to have positive, parental and supportive countertransference reactions in their work with adolescent patients, in line with hypothesis 3. Even though the clinical literature often describes feelings toward adolescents as "complex" and "very intense" (Sarles, 1994; Rasic, 2010), our results are in line with the most recent views of countertransference as a bipersonal experience of involvement of the therapist and patient (Safran, 2012). IAPP's view of the adolescent as facing difficult developmental tasks and maladapted, rather than impulse-driven, in turmoil and manifesting sexual or aggressive conflicts, results in a "role responsiveness" on the therapist's side (Sandler, 1976) thus explaining a benign, engaged and parental countertransference.

\section{Conclusion}

The study presents limits and perspectives. First, the sample is not representative of all the psychotherapists who may fall within the IAPP approach. We aim to extend the research to the majority of colleagues belonging to AGIPPsA. A further limit involves the procedure: we asked our sample to think about a "prototypical" adolescent psycho- 
therapy, rather than a specific patient.

The main methodological limitation of this study is in the choice of a "forced distribution". Despite the approximate fixed normal distribution of this Q-Methodology rating system ensures multiple evaluation of items and a ttenuates response set biases (e.g. halo-effects) often present with Likerttype methodology, it also requires formal training and reaching inter-rater reliability. To ensure a proper use of the instrument and reliable and valid results, this study should be replicated modifying Q-methodology and asking raters to rate each item in the manual on a Likert scale, from -4 to +4 (see Goodman, Midgley, \& Schneider, 2015; Leichsenring et al., 2015).

Future studies may target therapists specialised in the treatment of adolescents with diverse problems, such as young offenders, hikikomori (acute social withdrawal), youths with eating disorders. We might find diverse results.

A further perspective is to compare an "ideal" psychotherapeutic approach with what actually happens during the session, by applying APQ to the verbatim transcripts of the session as in single case studies (Ablon, \& Jones 2002). The present study aimed to capture what expert therapists think they are doing and how they conceptualize their work. As Jones and Pulos (1993) found out, what therapists think is leading to a positive outcome based on their theoretical perspective could not be associated with what is typical of that particular modality or with what empirical research points out as effective in that therapeutic approach. The AQP is developed instead to describe the unique, ideographic, and idiosyncratic interaction between a single therapist-patient dyad.

This study is an attempt to link empirical research and psychoanalytic theory of techniques in adolescence psychotherapy. We know that whether a specific technique is effective or not depends upon a number of factors involving the single patient (e.g. interpersonal style, personality pathology, defensive functioning). From our viewpoint, the life cycle phase the patient is facing should be included in those factors. It is still unclear whether techniques which are proven effective with adult patients (see Blagys, Hilsenroth, 2000), are useful in the psychotherapy of adolescent patients. For instance, in our findings, defense analysis was not central, despite the fact that studies targeting adult patients and using PQS showed its relevance (PQS item 36: "the therapist points out patient's use of defensive maneuvers"; Lingiardi, 2013). APQ can be considered an important reference for a better undestanding of which techniques and interventions can be implemented by adolescence psychotherapists to deal with the difficulties of their particular patients in an effective way.

The main limit regarding the use of the Therapist
Response Questionnaire is that it was not specifically designed for adolescent patients. Therefore, items regarding attitudes and emotional responses on the therapist's side are often informed by a longterm adult psychotherapy model and were difficult to apply to our sample. We were aware of such shortcomings, which were not easy to overcome, given the lack of validated countertransference instruments sensitive to age differences. Indeed, the TRQ-Adolescent Version (CQA; Satir et al., 2009) has only been used in a single study, with the specific target of young people with eating disorders.

\section{References}

Ablon, J.S., \& Jones, E.E. (2002). Validity of Controlled Clinical Trials of Psychotherapy: Findings from the NIMH Collaborative Study. The American Journal of Psychiatry, 159(5), 775-783.

Aliprandi, M., Pelanda, E., \& Senise, T. (1990). Psicoterapia breve di individuazione. La metodologia di Tommaso Senise nella consultazione con l'adolescente (Brief psychotherapy of individuation: the methodology of Tommaso Senise in the adolescent psychotherapy). Milano: Feltrinelli.

Allen, J.G., Fonagy, P., \& Bateman, A.W. (2008). Mentalizing in Clinical Practice. Arlington: American Psychiatric Publishing.

American Psychological Association (2013). Recognition of Psychotherapy Effectiveness. Psychotherapy , 50, 102-109.

Bambery, M., Porcerelli, J.H., \& Ablon, J.S. (2007). Measuring psychotherapy process with the Adolescent Psychotherapy Q-Set (APQ): Development and applications for training. Psychotherapy: Theory, Research, Practice, Training, 4, 405-422. doi: 10.1037/0033-3204.44.4.405

Bateman, A.W., \& Fonagy, P. (2006). Mentalisation-based treatment for borderline personality disorder: practical guide. Oxford: Oxford University Press.

Betan, E., Heim, A.K., Zittel, C., \& Westen, D. (2005). Countertransference phenomena and personality pathology in clinical practice: An empirical investigation. American Journal of Psychiatry, 162, 890-898.

Blagys, M. D., \& Hilsenroth, M. J. (2000). Distinctive features of shortterm psychodynamic- interpersonal psychotherapy: A review of comparative psychotherapy process literature. Clinical Psychology: Science and Practice, 7, 167-188. doi:10.1093/clipsy.7.2.167

Block, J. (1978). The Q-sort method in personality assessment and psychiatric research. Palo Alto: Consulting Psychologist.

Blos, P. (1962). On Adolescence. A Psychoanalytic Interpretation. New York: The Free Press.

Brandell, J.R. (1992). Countertransference phenomena in the psychotherapy of children and adolescents. In J.R. Brandell (Ed.), Countertransference in psychotherapy with children and adolescents (1st ed., 1-44). Jason Aronson Inc, Northvale.

Bychkova, T., Hillman, S., Midgley, N., \& Schneider, C. (2011). The psychotherapy process with adolescents: a first pilot study and preliminary comparisons between different therapeutic modalities using the Adolescent Psychotherapy Q-Set. Journal of Child Psychotherapy, 37(3), 327-348. doi: 10.1080/0075417X.2011.614754

Calderon, A., Midgley, N., Schneider, C., \& Target, M. (2013). Adolescent Psychotherapy Q-Set. Coding Manual. Unpublished manuscript. London: University College London, Anna Freud Centre.

Castonguay, L.G., \& Muran, J. (2015). Fostering collaboration between researchers and clinicians through building practice oriented research: An introduction. Psychotherapy Research, 
25, (1), 1-5. doi: 10.1080/10503307.2014.966348

Castonguay, L.G., Locke, B.D., \& Hayes, J.A. (2011). The centre for collegiate mental health: An example of a practice-research network in university counseling centres. Journal of College Student Psychotherapy, 25, 105-119. doi: 10.1080/87568225.2011.556929

Cicchetti, D., \& Choen, D.J. (2008). Developmental Psychopathology. New York: John Wiley.

Colli, A., Tanzilli, A., Dimaggio, G., \& Lingiardi, V. (2014). Patient personality and therapist response: An empirical investigation. American Journal of Psychiatry, 171, 102108. doi: 10.1176/appi.ajp.2013.13020224

Creed T., \& Kendall, P.C. (2005), Therapist alliancebuilding behavior within a cognitive-behavioral treatment of anxiety in youth. Journal of Consulting and Clinical Psychology, 73, 498-505.

Erikson, E. (1968). Identity, youth and crisis. New York: W. W. Norton Company.

Fauth, J. (2006). Towards more and better countertransference research. Psychotherapy: Theory, Research, Practice, Training, 43(1), 16-31. doi: 10.1037/0033-3204.43.1.16

Freud, S. (1905). Three essays on the theory of sexuality. New York: Avon Books.

Freud, A. (1936). Ego and the Mechanisms of Defense (The Writings of Anna Freud, Vol 2). Madison: International University Press.

Gabbard, G.O. (1995). Countertransference: The emerging common ground. International Journal of Psychoanaysis, $76,475-485$

Gelso, C.J., \& Hayes, J.A. (2007), Countertransference and the therapist's inner experience: Perils and possibilities. New Jersey: Lawrence Erlbaum Associates.

Goodman, G., Midgley, M., \& Schneider, C. (2015). Expert clinicians' prototypes of an ideal child treatment in psychodynamic and cognitive-behavioral therapy: Is mentalization seen as a common process factor?. Psychotherapy Research, 14, 1-12. doi: 10.1080/10503307.2015.1049672

Greenspan, S.I. (1997). Developmentally Based Psychotherapy. Madison: International Universities Press.

Havinghurst, R.J. (1972). Developmental tasks and education. London: Longman.

Hilsenroth, M.J., Cromer, T.D., \& Ackerman, S.J. (2012). How to make practical use of therapeutic alliance research in your clinical work. In R.A. Levy, J.S. Ablon, \& H. Kachele (Eds.), Psychodynamic Psychotherapy Research. New York: Humana Press.

Jeammet, P. (1980). Réalité externe et réalité interne. Importance et spécificité de leur articulation à l'adolescence. Revue française de psychanalyse, 44(3-4), 481-522.

Jones, E.E. (2000). Therapeutic action: A guide to psychoanalytic therapy. Northvale: Aronson.

Jones, E.E., \& Pulos, S.M. (1993). Comparing the process in psychodynamic and cognitive-behavioral therapies. Journal of Consulting and Clinical Psychology, 61, 306-316.

Kazdin, A.E. (2004). Psychotherapy for children and adolescents. In MJ Lambert (Ed.), Bergin \& Garfield's handbook of psychotherapy and change (5th edition, 543-589). New York, John Wiley.

Kazdin, A.E. (2007). Mediators and mechanisms of change in psychotherapy research. Annual Review of Clinical Psychology, 3, 1-27.

Leichsenring, F., Ablon, S., Barber, J.P., Beutel, M., Connolly Gibbons, M.B., Crits-Christoph, P., Klein, S., Leweke, F., Steinert, C., Wiltink, J., \& Salzer, S. (2015). Developing a prototype for short-term psychodynamic (supportiveexpressive) therapy: An empirical study with the psychotherapy process Q-set. Psychotherapy Research, 28, 1-11. http://dx.doi.org/10.1080/10503307.2015.1051160

Lancini, M. (2010). Cent'anni di psicoanalisi (One hundred years of Psychoanalysis). Milano: Franco Angeli.
Levi, R.A., \& Ablon, J.S. (2009). Handbook of evidence-based Psychodynamic Psychotherapy. New York: Human Press.

Levi, R.A., Ablon, J.S., \& Kachele, H. (2011). Psychodynamic Psychotherapy Research. New York: Human Press.

Lingiardi, V. (2013). Trying to be useful: three different interventions for one therapeutic stance. Psychotherapy, 50 (3), 413-418. doi: 10.1037/a0032195.

Maggiolini, A. (2009). Ruoli affettivi e psicoterapia (Affective roles and psychotherapy). Milano: Raffaello Cortina.

Maggiolini, A. (2012). Quale futuro per la psicoanalisi dell'adolescenza? (What about the future of adolescent psychoanalysis?). Presentazione al X Convegno Nazionale di Psicoterapia Psicoanalitica dell'Adolescenza AGIPPsA, Roma, 13-14 ottobre.

Maggiolini, A. (2014). Senza paura, senza pietà (Without fear, without mercy). Milano: Raffaello Cortina.

Maggiolini, A., \& Pietropolli Charmet, G. (2004). Manuale di psicologia dell'adolescenza (Handbook of Adolescence Psychology). Milano: Franco Angeli.

McLeod, B.M., \& Weisz, J.R. (2005). The Therapy Process Observational Coding System Alliance scale: measure characteristics and prediction of outcome in 'usual clinical practice'. Journal of Consulting and Clinical Psycholo$g y, 73,323-333$.

Novelletto, A. (1986). Psichiatria psicoanalitica dell'adolescenza (Adolescent Psychoanalytic Psychiatry). Roma: Borla.

Pellizzari, G. (2003). La psicoanalisi degli adolescenti ha cambiato la tecnica psicoanalitica? (Did the adolescent psychoanalysis changed psychoanaltic technique?). Adolescenza e Psicoanalisi, 3, 1. www.psychomedia.it/aep/ 2003/numero-1/pellizzari.htm

Pietropolli Charmet, G., Bignamini, S., \& Comazzi, D. (2010). Psicoterapia evolutiva dell'adolescente (Developmental psychotherapy for adolescents). Milano: Franco Angeli.

Rasic D (2010). Countertransference in child and adolescent psychiatry: A forgotten concept?. Journal of the Canadian Academy of Child and Adolescent Psychiatry, 19(4), 249-254.

Safran, J.D. (2012). Psychoanalysis and Psychoanalytic Therapies. Washington: American Psychological Association.

Safran, J.D., Abreu, I., Ogilvie, J., \& DeMaria, A. (2011). Does psychotherapy research influence the clinical practice of researcher-clinicians? Clinical Psychology: Science \& Practice, 18, 357-371. doi:10.1176/appi.ps.60.5.671

Safran, J.D., \& Muran, J.C. (2000). Negotiating the therapeutic alliance: a relational treatment guide. New York: Guilford Press.

Sandler, J. (1976). Countertransference and Role-Responsiveness. International Review of Psycho-Analysis, 3: 43-47.

Sarles, R.M. (1994). Transference-countertransference issues with adolescents: personal reflections. American Journal of Psychotherapy, 48(1), 64-74.

Satir, D.A., Thompson-Brenner, H., Boisseau, C.L., \& Crisafulli, M. (2009), Countertransferencreactions to adolescent eating disorder patients: Relationships to symptoms and personality. International Journal of Eating Disorders, 42, 511-521. doi: 10.1002/eat.20650

Shirk, S., Karver, M., \& Brown, R. (2011). The alliance in child and adolescent psychotherapy: A meta-analysis. Psychotherapy, Theory, Research and Practice, 48, 17-24.

Showalter, J.E. (1985). Countertransference in work with children: Review of a neglected concept. Journal of the American Academy of Child Psychiatry, 25(1), 40-45

Tanzilli, A., Colli, A., Muzi, L., \& Lingiardi, V. (2015). Clinician emotional response toward narcissistic patients: A preliminary report. Research in Psychotherapy: Psychopathology, Process and Outcome, 18(1), 1-9.

Torres, N.M., \& Ribeiro, A.E. (2012). Implementing clinical monitoring of psychodynamic psychotherapy in a public community centre for young people: Service issues in bridging practice and evidence. Paper presented at the 3rd Join Meeting of 
the SPR European and UF Chapters, Porto, Portugal.

Town, J.M., Diener, M.J., Abbass, A., Leichsenring, F., Driessen, E., \& Rabung, S. (2012). A Meta-Analysis of Psychodynamic Psychotherapy Outcomes: Evaluating the Effects of Research-Specific Procedures. Psychotherapy, 49(3), 276-290. doi: 10.1037/a0029564

Westen, D., \& Gabbard, G.O. (2002). Developments in cognitive neuroscience: II. Implications for theories of transference. Journal of the American Psychoanalytic Association, 50, 99-134.

Winnicott, D.W. Deprivation and Delinquency London: Tavistock.
Zack, S.E., Castonguay, L.G., Boswell, J.F., McAleavey, A.A., Adelman, R., Kraus, D.R., \& Pate, G.A. (2015). Attachment history as a moderator of the alliance outcome relationship in adolescents. Psychotherapy, 52(2), 258-267. doi: $10.1037 / \mathrm{a} 0037727$

Zittel, C., \& Westen, D. (2003). The therapist response questionnaire. Atlanta: Emory University, Departments of Psychology and Psychiatry and Behavioral Sciences.

Submitted: July 2015

Accepted: November 2015

Published: December 2015 